\title{
Theoretical and experimental investigation of an absorption refrigeration and pre-desalination system for marine engine exhaust gas heat recovery
}

\author{
Han Yuan ${ }^{1 *}$, Pengyuan Sun ${ }^{1}$, Ji Zhang ${ }^{1}$, Kunyuan Sun ${ }^{1}$, Ning Mei ${ }^{1}$ and Peilin Zhou $^{2}$
}

1. College of Engineering, Ocean University of China, 238 Songling Road, Laoshan

district, Qingdao 266100, China

2. Department of Naval Architecture and Marine Engineering, University of Strathclyde, Glasgow G4 OLZ, United Kingdom

Phone/Fax: +86-532-66781105,

E-mail: hanyuan@ ouc.edu.cn

Address: 238 Songling Road, Laoshan district, Qingdao 266100, China

\section{Abstract}

Absorption-refrigeration-cycle-based exhaust gas heat recovery technology is effective in improving the thermal efficiency and fuel economy of marine diesel engines.

However, the absorption refrigeration system is inflexible in the start-stop operation, and this cannot fulfil the fluctuating demand of refrigeration. This paper presents both the theoretical and experimental investigations of an absorption refrigeration and freezing pre-desalination-based marine engine exhaust gas heat recovery system. The energy storage subcycle is introduced to overcome the energy underutilisation and balance the excessive refrigerating output of the absorption refrigeration cycle. 
Seawater is utilised as the phase-change material and it is pre-desalinated in the energy storage subcycle. A mathematical model of the system is established and experimental investigation is conducted. Furthermore, the theoretical and experimental performances are compared, and an economic analysis of seawater desalination is performed to evaluate its economy. The results show that the total refrigeration output of the system ranges from $6.1 \mathrm{~kW}$ to $9.9 \mathrm{~kW}$, and the system COP (Coefficient of Performance) can reach $16 \%$ under the experimental operating conditions. Additionally, the salinity of pre-desalinated seawater can be reduced to below $10 \mathrm{ppt}$. Moreover, the cost of RO (Reverse Osmosis) seawater desalination can be reduced by $26 \%$ through the predesalination process of seawater.

Keywords: Marine diesel engine; Exhaust gas heat recovery; Absorption refrigeration; Ammonia-water; Seawater freezing desalination

\begin{tabular}{|l|}
\hline Nomenclature \\
Symbols \\
$B$ \\
$F$ \\
$G$ \\
$J$ \\
$P$ \\
$Q$ \\
$T$ \\
$U$ \\
$X$ \\
$Z$ \\
$c_{p}$ \\
$h$ \\
$m$ \\
$n$
\end{tabular}

ratio of washing water to sea ice

cost, yuan

reflux ratio

icing rate

pressure, $\mathrm{MPa}$

heat load, $\mathrm{kW}$

temperature, ${ }^{\circ} \mathrm{C}$

circulation ratio

solution concentration, $\mathrm{kg} / \mathrm{kg}$

refrigeration ratio between evaporator I and II

seawater specific heat, $\mathrm{kJ} /\left(\mathrm{kg}^{\circ} \mathrm{C}\right)$

specific enthalpy, $\mathrm{kJ} / \mathrm{kg}$

mass flow rate, $\mathrm{kg} / \mathrm{s}$

desalinization ratio 


\begin{tabular}{|c|c|}
\hline$q$ & specific heat load, $\mathrm{kJ} / \mathrm{kg}$ \\
\hline$s$ & seawater salinity, ppt \\
\hline \multicolumn{2}{|c|}{ Greek Symbols } \\
\hline$\alpha$ & rate of pre-desalinated water output, $\%$ \\
\hline$\Delta$ & temperature difference, ${ }^{\circ} \mathrm{C}$ \\
\hline \multicolumn{2}{|l|}{ Subscripts } \\
\hline$R$ & reflux condenser \\
\hline$a$ & absorber \\
\hline$c$ & condenser \\
\hline$e$ & evaporator \\
\hline$g$ & generator \\
\hline$i=1,2,3 \ldots$ & state points \\
\hline$r$ & rich solution \\
\hline$w$ & weak solution \\
\hline ps & pre-desalinated seawater \\
\hline$s h$ & solution heat exchanger \\
\hline sw & seawater \\
\hline$w w$ & washing water \\
\hline con & condensation \\
\hline ice & sea ice \\
\hline mem & RO membrane \\
\hline ref & refrigerant \\
\hline elec & electricity \\
\hline \multicolumn{2}{|l|}{ Acronyms } \\
\hline$A B S$ & absorber \\
\hline AM-TANK & ammonia tank \\
\hline CAP & capillary \\
\hline$C O N$ & condenser \\
\hline CO-STO & cold storage \\
\hline$D E P$ & dephlegmator \\
\hline$E V A P$ & evaporator \\
\hline GEN & generator \\
\hline$H-E X C H$ & solution heat exchanger \\
\hline NOZ & nozzle \\
\hline$R E F-C O N$ & reflux condenser \\
\hline$R O-D$ & RO device \\
\hline TH-TANK & thawing tank \\
\hline$V I B-S E P$ & vibrant separator \\
\hline fre-water & fresh water \\
\hline gas-in & exhaust gas inlet \\
\hline gas-out & exhaust gas outlet \\
\hline
\end{tabular}




\begin{tabular}{|ll|}
\hline pre-water & pre-desalinated seawater \\
was-water & washing water \\
water-in & cooling water inlet \\
w-out & cooling water outlet \\
\hline
\end{tabular}

\section{Introduction}

Marine diesel engines have been widely used as the primary power suppliers for fishing and merchant ships[1]. When a marine diesel engine operates in the zone of good efficiency, only $30-45 \%$ of the energy obtained by fuel combustion can be transferred into shaft power output[2-4], while approximately one third of the energy is wasted along with the exhaust gases[5]. Consequently, the waste heat recovery of engine exhaust gas is important for improving the fuel efficiency and achieving the goal of energy conservation in marine diesel engines[6, 7]. In addition, it aids in environmental protection by reducing carbon dioxide emissions[8].

Among the several exhaust gas heat recovery technologies available, absorption refrigeration cycle technology has proven to be the most effective as it converts exhaust heat energy into refrigeration output $[9,10]$. Generally, the absorption refrigeration cycle is categorised into two types: the lithium-bromide-based absorption refrigeration cycle[11] and the ammonia-water-based absorption refrigeration cycle[12]. Owing to the crystallisation in the operating fluid, the refrigeration temperature of lithiumbromide-based absorption refrigeration cycle remains above zero[13-15], while the refrigeration temperature of an ammonia-water-based cycle can reach approximately $-30{ }^{\circ} \mathrm{C}[16-18]$ and can be used for cryogenic refrigeration[19]. Therefore, the ammonia-water-based cycle is more competitive for marine cryogenic refrigeration, particularly for fishing ship refrigeration. 
However, the disadvantage of ammonia-water-based absorption refrigeration cycle that is driven by exhaust gas is obvious: after the temperature of cold storage reaches the predetermined refrigerating temperature, the refrigeration demand of cold storage declines to a low level. While the electric compression refrigeration system can adopt an intermittent operation strategy to adapt to the fluctuation of the refrigeration demand[20], the absorption refrigeration system is more inflexible as it is driven by the exhaust gas and its cooling capacity can become redundant. Therefore, it is important to balance the excessive refrigerating output.

To solve this problem, ice thermal storage technology can be considered. Ice thermal storage technology is a type of phase-change energy storage technology[21, 22]. By storing the redundant cooling capacity in the form of an ice slurry[23, 24], the refrigerating output can be fully utilised. If seawater is used as the phase-change material, it can be pre-desalinated owing to the freezing desalination phenomenon. Freezing desalination is based on the fact that salt is separated during the formation of ice crystals. Fresh water can then be produced by harvesting and melting the ice crystals[25-27]. The technology of freezing desalination was first applied in food concentration. In 1961, Shapiro applied the freezing concentration method to an experiment that concentrated organic compounds[28]. Currently, using the freezing method for seawater desalination has attracted wide attention. Anouar Rich et al. [29] improved the purity of sea ice using partial melting to drain out trapped brine pockets. Cong-shuang Luo et al. [30] employed unidirectional freezing to create layered ice and subsequently improved the quality of ice through crushing and centrifugation. In 
general, seawater freezing desalination is effective in terms of energy utilisation, and has many advantages in comparison to other conventional technologies[31]. After the process of freezing desalination, the salinity of seawater will be significantly reduced. This is important in the application of the absorption refrigeration system on board a ship. With a lower level of salinity in seawater, the operation pressure of the RO device can significantly be decreased. On the one hand, the service life of the RO membrane is extended; while the operation power of the high-pressure pump is decreased. The factors above can effectively reduce the cost of RO seawater desalination.

Herein, an absorption refrigeration and freezing pre-desalination system for marine engine exhaust gas heat recovery is proposed. In this system, waste heat from the internal combustion engine exhaust gas is used to drive the ammonia-absorption refrigeration cycle. When the cooling capacity is provided, the partial cooling capacity is used for seawater pre-desalination according to the seawater freezing desalination principle, and the remaining cooling capacity is used to conserve food in cold storage. This system avoids the waste of exhaust gas energy through incessant seawater predesalination, which can be deemed as a disguised energy-storage technology. In addition, the mathematical model of the absorption refrigeration and pre-desalination system for marine engine exhaust gas heat recovery is established, and the performance of the system is theoretically analysed. Furthermore, an experimental platform is built and experimental tests are conducted. The theoretical and experimental results are compared, and an economic analysis of seawater desalination is performed to evaluate its economy. 


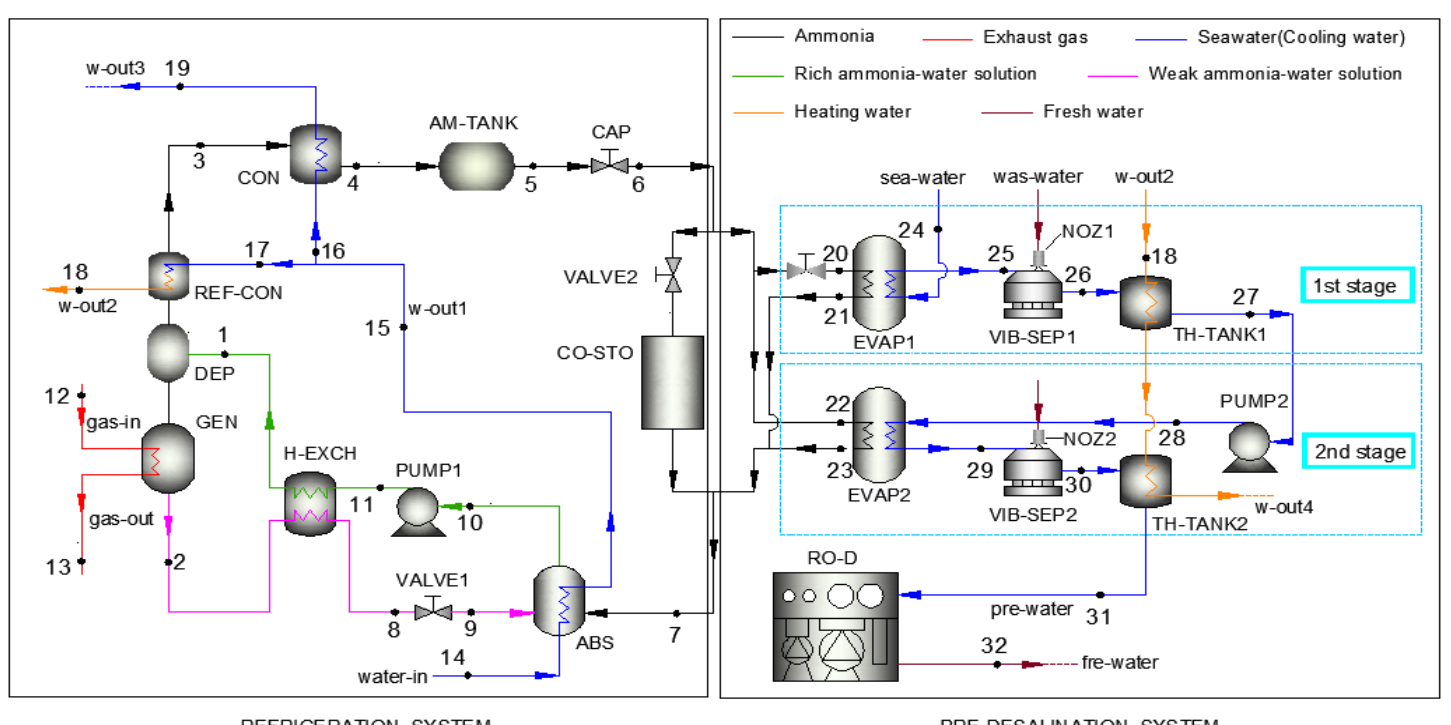

103

104

105

Fig.1 Schematic of the absorption refrigeration and two-stage freezing-assisted desalination system (the abbreviations in the figure can be found in the nomenclature section)

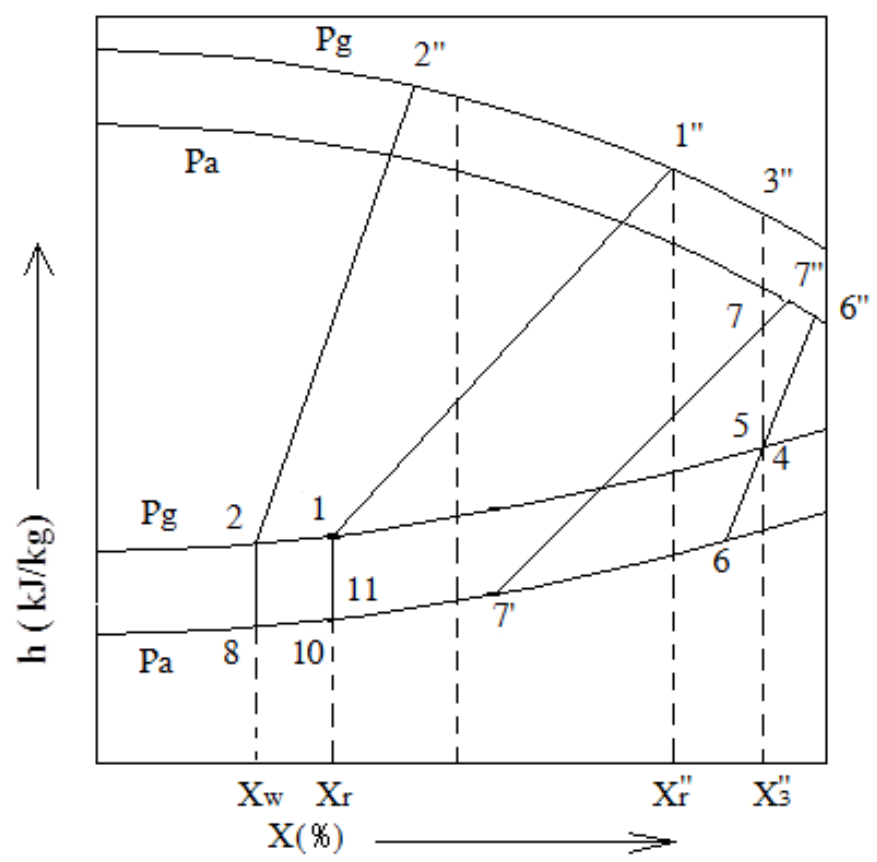

Fig. $2 \mathrm{~h}-\mathrm{X}$ diagram of the refrigeration cycle

Figure 1 shows a schematic of the combined system and Fig. 2 shows the $\mathrm{h}-\mathrm{X}$ 
110

111

112

113

114

115

116

117

118

119

120

121

122

123

124

125

126

127

128

129

130

131

diagram of the refrigeration cycle. The proposed system consists of the following primary components:

- A generator

- A dephlegmator

- A reflux condenser

- A condenser

- An ammonia tank

- An absorber

- A heat exchanger

- A capillary

- A cold storage

- A solution pump

- Two evaporators

- Two vibrant separators

- Two thawing tanks

- Two nozzles

- Three valves

The absorption refrigeration and two-stage freezing-assisted desalination system contains two subsystems: refrigeration subsystem and pre-desalinated subsystem. The refrigeration subsystem is a single-stage ammonia-water absorption refrigeration system, which is driven by marine engine exhaust gas heat. The pre-desalinated subsystem is a two-stage seawater freezing-assisted desalination system. In the pre- 
desalinated subsystem, seawater is used as the phase-change energy storage material and it is pre-desalinated owing to the freezing desalination phenomenon.

The detailed process description of the combined system is as follows:

In the refrigeration system, the high-temperature flue gas produced by the marine diesel engine is used as a heating source. In the generator, a high-temperature and highpressure ammonia-water mixture is generated and subsequently, successively passed through the dephlegmator and reflux condenser. The high-temperature ammonia vapour is separated from the ammonia-water mixture, before entering the condenser and the capillary to further reduce the temperature. In this process, the ammonia vapour becomes a low-temperature ammonia liquid. Next, the ammonia liquid flows into two branches to produce refrigeration: the cold storage branch and the freezing desalination branch. After evaporation to the two branches above, the ammonia vapour is mixed and flows into the absorber. Meanwhile, the separated weak ammonia-water solution is cooled down in the solution heat exchanger, and it is subsequently passed through the throttle valve to reduce pressure, before flowing into the absorber to produce a rich solution. The cooling water is used to eliminate the heat generated in the absorption process and to remove the heat of condensation in the condenser and reflux condenser. Finally, the rich solution at a relatively low temperature and pressure is pumped into the generator after being heated in the solution heat exchanger.

In the pre-desalination system, a two-stage freezing-assisted desalination approach is adopted. First, a part of the ammonia liquid is evaporated in evaporator I to produce first-level refrigeration. The initial seawater is turned into an ice water mixture after 
acquiring the first-level refrigeration. The ice water mixture enters vibrant separator I through the outlet of evaporator I to separate. Simultaneously, fresh water from the nozzle washes the sea ice to reduce its salinity. This part of the fresh water is also considered in the final economic analysis. Subsequently, the sea ice enters thawing tank I to exchange heat with the relatively high-temperature cooling water from the reflux condenser outlet. After thawing, the seawater with an initial reduction in salinity is pumped into evaporator II to acquire second-level refrigeration. Meanwhile, the remaining ammonia liquid evaporates completely. The ice water mixture formed in this process enters vibrant separator II and thawing tank II successively to repeat the steps above, further reducing the salinity of the pre-desalinated seawater. Finally, the ammonia liquid in the desalination branch evaporates completely. The ammonia vapour from the desalination branch, along with the ammonia vapour from the cold storage branch, flow into the absorber together.

\section{Thermodynamic analysis of the combined system}

A thermodynamic analysis was conducted to assess the performance of the combined refrigeration and pre-desalination system. A mathematical model was established, where a program was developed to solve the equations.

\subsection{Basic assumptions}

The following assumptions were used in the system modelling:
(1) Each component of this combined system is in a steady state. 
(2) The heat losses in the system are negligible.

(3) The fluid expansion in the throttling valve is considered isenthalpic.

(4) The ammonia-water solution/vapour at the output of both the absorber and reflux condenser are saturated.

\subsection{Mathematical model}

The mathematical model for this combined system was established based on the first law of thermodynamics, and an energy analysis was conducted to evaluate the theoretical performance of this combined system.

The mass balance equations in the system are given as follows:

$$
\left(\sum m_{i}\right)_{\text {in }}=\left(\sum m_{i}\right)_{\text {out }} ;
$$

$$
\left(\sum X_{i} \cdot m_{i}\right)_{\text {in }}=\left(\sum X_{i} \cdot m_{i}\right)_{\text {out }} .
$$

The energy balance equations for the system are given as follows:

The reflux ratio is defined as

$$
\mathrm{G}=m_{2} / m_{3} .
$$

The degassing range is defined as

$$
\Delta \mathrm{X}=X_{r}-X_{w} .
$$

The circulation ratio is defined as

$$
\mathrm{U}=\left(X_{3}-X_{w}\right) /\left(X_{r}-X_{w}\right) .
$$

The unit heat exchange and total heat exchange of the reflux condenser are

$$
q_{R}=h_{1}^{\prime \prime}-h_{3}+G\left(h_{1}^{\prime \prime}-h_{1}\right) ;
$$

$$
Q_{R}=m_{3} \cdot q_{R},
$$



ammonia-water solution at point 1 .

197 The unit heat exchange and total heat exchange of the generator are

$$
q_{g}=h_{3}-h_{2}+U\left(h_{2}-h_{1}\right)+q_{R}
$$

$Q_{g}=m_{3} \cdot q_{g}$

The unit heat exchange and total heat exchange of the condenser are

$$
q_{c}=h_{3}-h_{4}
$$

$$
Q_{c}=m_{3} \cdot q_{c}
$$

203 The unit heat exchange and total heat exchange of the absorber are

$$
q_{a}=h_{7}-h_{9}+U\left(h_{9}-h_{10}\right)
$$

The unit refrigerating capacity and total refrigerating capacity are

$$
q_{e}=h_{7}-h_{5}
$$

$Q_{e}=m_{3} \cdot q_{e}$

209 The unit heat exchange and total heat exchange of the solution heat exchanger are

$q_{s h}=(U-1)\left(h_{2}-h_{8}\right)$

$Q_{s h}=m_{3} \cdot q_{s h}$

The system coefficient of performance (COP) is

214 The energy balance equation for the system is

$$
Q_{e}+Q_{g}=Q_{R}+Q_{c}+Q_{a}
$$

The analysis for the seawater side of the desalination branch is given as follows: 

according to the refrigeration ratio Z,

$$
Q_{1}=\frac{Z}{Z+1} Q_{e d}
$$

The refrigeration of evaporator II is

$$
Q_{2}=\frac{1}{Z+1} Q_{e d}
$$

For evaporator I: $T_{s w 1}$ is the seawater inlet temperature; $T_{s w 2}$ is the outlet is the unit condensation heat of seawater. The mass flow rate of the seawater to be desalinated $m_{s w 1}$ can be calculated according to the refrigeration.

$$
Q_{1}=c_{p} m_{s w 1}\left(T_{s w 1}-T_{s w 2}\right)+m_{\text {ice } 1} \cdot q_{c o n}
$$

$$
m_{i c e 1}=J_{1} \cdot m_{s w 1}
$$

The mass flow rate of the seawater entering evaporator $I m_{s w 1}$ can be acquired according to equation (22) and equation (23).

The mass flow rate of the seawater entering evaporator II is

$$
m_{s w 2}=m_{\text {ice } 1}
$$

The mass flow rate of the washing water consumed by the first desalination process is

$$
m_{w w 1}=B_{1} \cdot m_{i c e 1}
$$

The initial salinity of the seawater is defined as $s_{1}$. After the first desalination process, the salinity of the seawater is defined as $s_{2}$, and the desalination ratio is 
For evaporator II: $T_{s w 3}$ is the seawater inlet temperature; $T_{s w 4}$ is the outlet refrigerating capacity of evaporator II $Q_{s w 2}$ can be acquired according to the calculation results above. evaporator I should gradually be reduced, and subsequently the calculation steps above should be repeated to obtain the new values of $Q_{s w 1}$ and $Q_{s w 2} \cdot Q_{s w 1}$ and $Q_{s w 2}$ are the ultimate refrigerating capacities of evaporators I and II, respectively.

$$
m_{p s}=m_{\text {ice } 2}
$$
ratio is

$$
n_{2}=\frac{s_{2}-s_{3}}{s_{2}} \times 100 \% \text {. }
$$

257 After the complete desalination process, the total desalination ratio is

$$
\mathrm{n}=\frac{s_{1}-s_{3}}{s_{1}} \times 100 \%
$$

The output ratio of the pre-desalinated seawater with low salinity is

$$
\alpha=\frac{m_{p s}}{m_{s w 1}} \times 100 \% .
$$



based on the following substep of the desalination experiment.

The analysis for the refrigerant side of the desalination branch is given as follows:

$m_{\text {ref }}=m_{\text {ref } 1}+m_{\text {ref } 2}$.

Assuming that the temperature of the refrigerant before entering the evaporator is $T_{\text {ref } 1}$, the enthalpy of the saturated ammonia liquid is $h_{r e f 1}$. After evaporation, the temperature of the ammonia vapour increases to $T_{\text {ref } 2}$, and the enthalpy of the saturated ammonia vapour is $h_{r e f 2}$. According to the above analysis, the refrigerating capacities of evaporators I and II are $Q_{s 1}$ and $Q_{s 2}$, respectively. Subsequently, the mass flow rates of the evaporated refrigerant for evaporators I and II, respectively, are

A program was developed to analyse the system performance; Fig. 3 shows the calculation strategy for the refrigeration system. In this program, a database was compiled based on the Sulze equation[32] to calculate the thermodynamic variables of the ammonia-water and ammonia vapour. Table 1 shows the initial parameters for the simulation. 


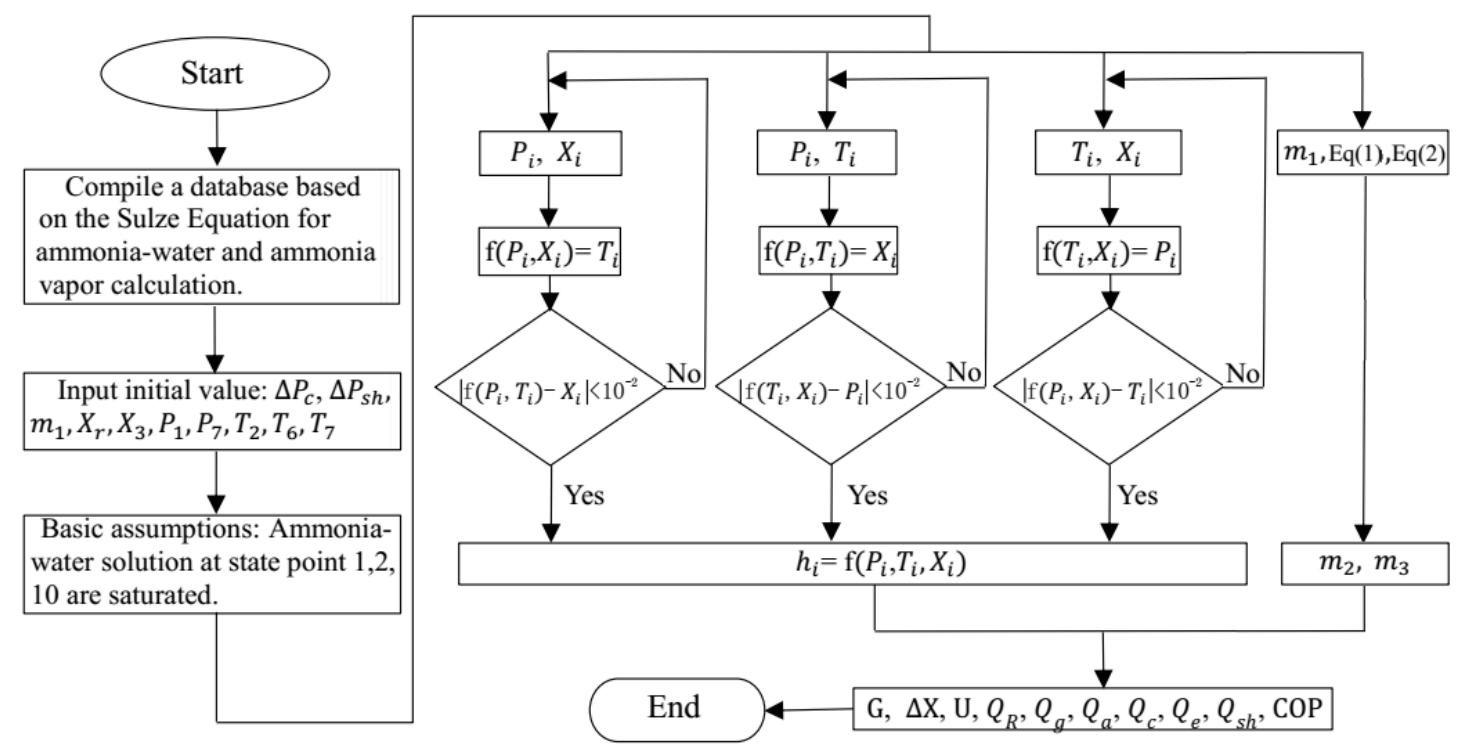

Fig. 3 Solution procedure for the refrigeration system

Table 1 Initial parameters for simulation

\begin{tabular}{llll}
\hline Diesel engine specification & $200 \mathrm{~kW}$ & Generation temperature & $150^{\circ} \mathrm{C}$ \\
Evaporation temperature & $-18^{\circ} \mathrm{C}$ & Cooling water temperature & $25^{\circ} \mathrm{C}$ \\
Rich solution concentration & $0.28 \mathrm{~kg} / \mathrm{kg}$ & Rich solution mass flow rate & $40 \mathrm{~g} / \mathrm{s}$ \\
$\begin{array}{l}\text { Generation pressure } \\
\begin{array}{l}\text { Pressure difference between } \\
\text { generator and condenser }\end{array}\end{array}$ & $1.0 \mathrm{MPa}$ & $\begin{array}{l}\text { Absorption pressure } \\
\text { Pressure drop of solution heat } \\
\text { exchanger }\end{array}$ & $0.1 \mathrm{MPa}$ \\
\hline
\end{tabular}

To obtain the details of the thermodynamic performance of the refrigeration system, a simulation under a typical operating condition was performed. Table 2 shows the simulation results of each state point in the refrigeration system at a typical operating condition. In addition, the performance of the refrigeration system with this typical operating condition is shown in Table 3.

Table 2 Results of simulation at typical operating condition

\begin{tabular}{cccccc}
\hline State & $\mathrm{X}(\mathrm{kg} / \mathrm{kg})$ & $\mathrm{P}(\mathrm{MPa})$ & $\mathrm{T}\left({ }^{\circ} \mathrm{C}\right)$ & $\mathrm{H}(\mathrm{kJ} / \mathrm{kg})$ & $\mathrm{M}(\mathrm{g} / \mathrm{s})$ \\
\hline 1 & 0.28 & 1 & 104 & 350 & 40 \\
2 & 0.12 & 1 & 150 & 570 & 32.7 \\
3 & 1.00 & 1 & 55 & 1792 & 7.3
\end{tabular}




\begin{tabular}{cccccc}
4 & 1.00 & 1.1 & 30 & 639 & 7.3 \\
5 & 1.00 & 1.1 & 30 & 639 & 7.3 \\
6 & 1.00 & 0.1 & -18 & 418 & 7.3 \\
7 & 1.00 & 0.1 & -15 & 1743 & 7.3 \\
8 & 0.12 & 0.8 & 80 & 250 & 32.7 \\
9 & 0.12 & 0.1 & 80 & 250 & 32.7 \\
10 & 0.28 & 0.1 & 32 & 25 & 40 \\
11 & 0.28 & 1.2 & 32 & 88 & 40 \\
\hline
\end{tabular}

290

291 Table 3 Performance of the refrigeration system

\begin{tabular}{ll}
\hline Reflux ratio & 4.5 \\
Degassing range $(\mathrm{kg} / \mathrm{kg})$ & 0.16 \\
Circulation ratio & 5.5 \\
Dephlegmator heat output $(\mathrm{kW})$ & 52.7 \\
Generator heat input $(\mathrm{kW})$ & 70.5 \\
Condenser heat output $(\mathrm{kW})$ & 8.4 \\
Absorber heat output $(\mathrm{kW})$ & 19.9 \\
Refrigeration output $(\mathrm{kW})$ & 8.1 \\
COP $(\%)$ & 11.5 \\
\hline
\end{tabular}

The relationship between the total refrigerating capacity of the desalination branch in Fig. 4 is obtained from a variable-condition analysis by a further solution program.

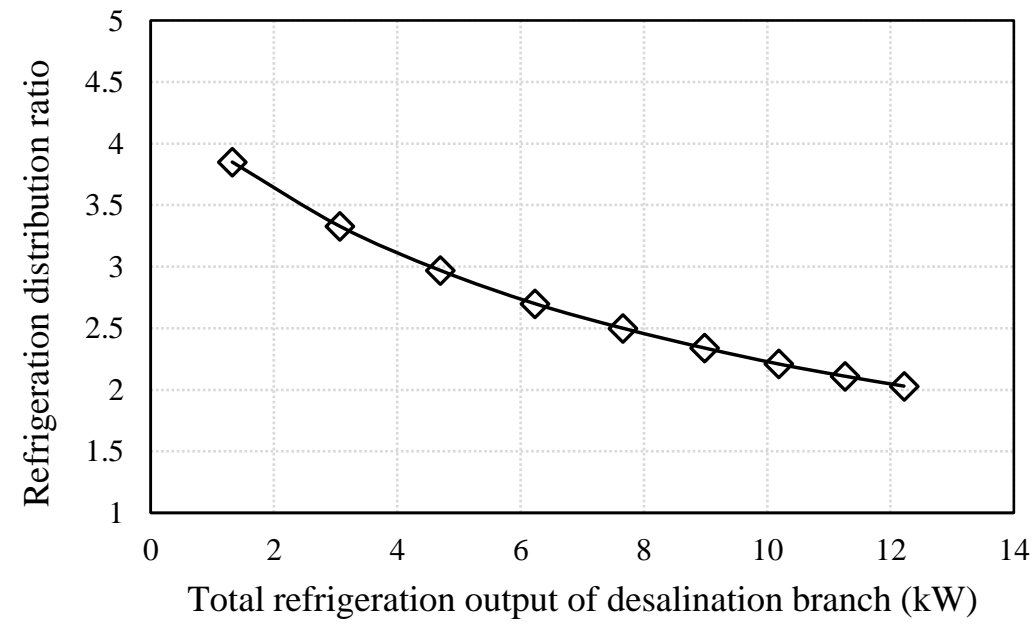

Fig.4 Relationship between the total refrigeration capacity in desalination branch 
An experimental analysis of the combined system was performed, including an plan and results.

\subsection{Uncertainty analysis}

A set of instruments were mounted on each component. The instruments consist of parameters of the instruments are listed in Table 4.

Table 4 Parameters of instruments

\begin{tabular}{ll}
\hline K-type thermocouple & -40 to $1200{ }^{\circ} \mathrm{C}, \pm 0.5 \%$ \\
Pressure gauge & $0-1.5 \mathrm{MPa}, \pm 0.5 \%$ \\
Flowmeter for liquid ammonia & $10-100 \mathrm{~L} / \mathrm{h}, \pm 1.0 \%$ \\
Flue gas analyser & $\mathrm{O}_{2}, \mathrm{CO}_{2}, \mathrm{~N}_{2}, \pm 1.0 \%$ \\
Flowmeter for water & $0.10-10 \mathrm{~m} / \mathrm{h}, \pm 1.5 \%$ \\
Flowmeter for exhaust gas & $0-120 \mathrm{~m} / \mathrm{s}, \pm 1.0 \%$ \\
\hline
\end{tabular}

The uncertainty analysis is based on the theory of error propagation and the root-

$$
\frac{\mu_{C O P}}{C O P}=\sqrt{\left(\frac{\mu_{Q_{e}}}{Q_{e}}\right)^{2}+\left(\frac{\mu_{Q_{g}}}{Q_{g}}\right)^{2}}
$$$$
\frac{\mu_{Q_{e}}}{Q_{e}}=\sqrt{\left(\frac{\mu_{m_{3}}}{m_{3}}\right)^{2}+\left(\frac{\mu_{h_{5}}}{h_{5}}\right)^{2}+\left(\frac{\mu_{h_{7}}}{h_{7}}\right)^{2}}
$$

$$
\frac{\mu_{Q_{R}}}{Q_{R}}=\sqrt{\left(\frac{\mu_{m_{3}}}{m_{3}}\right)^{2}+\left(\frac{\mu_{h_{1}^{\prime \prime}}}{h_{1}^{\prime \prime}}\right)^{2}+\left(\frac{\mu_{h_{1}}}{h_{1}}\right)^{2}+\left(\frac{\mu_{h_{3}}}{h_{3}}\right)^{2}+\left(\frac{\mu_{G}}{G}\right)^{2}}
$$

$$
\frac{\mu_{Q_{a}}}{Q_{a}}=\sqrt{\left(\frac{\mu_{m_{3}}}{m_{3}}\right)^{2}+\left(\frac{\mu_{h_{7}}}{h_{7}}\right)^{2}+\left(\frac{\mu_{h_{9}}}{h_{9}}\right)^{2}+\left(\frac{\mu_{h_{10}}}{h_{10}}\right)^{2}+\left(\frac{\mu_{U}}{U}\right)^{2}}
$$

$$
\frac{\mu_{Q_{c}}}{Q_{c}}=\sqrt{\left(\frac{\mu_{m_{3}}}{m_{3}}\right)^{2}+\left(\frac{\mu_{h_{3}}}{h_{3}}\right)^{2}+\left(\frac{\mu_{h_{4}}}{h_{4}}\right)^{2}}
$$




$$
\frac{\mu_{G}}{G}=\sqrt{\left(\frac{\mu_{m_{2}}}{m_{2}}\right)^{2}+\left(\frac{\mu_{m_{3}}}{m_{3}}\right)^{2}}
$$

$$
\frac{\mu_{U}}{U}=\sqrt{\left(\frac{\mu_{X_{3}}}{X_{3}}\right)^{2}+\left(\frac{\mu_{X_{r}}}{X_{r}}\right)^{2}+\left(\frac{\mu_{X_{w}}}{X_{w}}\right)^{2}}
$$

$$
\mu_{X}=\sqrt{\left(X\left(T+\mu_{T}, P\right)-X(T, P)\right)^{2}+\left(X\left(T, P+\mu_{P}\right)-X(T, P)\right)^{2}}
$$

$\mu_{h}=\sqrt{\left(h\left(T+\mu_{T}, P, X\right)-h(T, P, X)\right)^{2}+\left(h\left(T, P+\mu_{P}, X\right)-h(T, P, X)\right)^{2}+\left(h\left(T, P, X+\mu_{X}\right)-h(T, P, X)\right)^{2}}$

The resulting uncertainty in the COP is $3.8 \%$. The uncertainty in the refrigerating capacity is $1.7 \%$.

\subsection{Experimental plan}

The experimental plan includes the general system experimental plan and predesalination system experimental plan.

\subsubsection{Experimental plan for combined system}

The experimental platform for this combined system was constructed. A certain proportion of water and pure ammonia vapour were injected into the system, and the concentration of the formed rich solution was $0.28 \mathrm{~kg} / \mathrm{kg}$. Compared to the concentration of rich ammonia-water solution in traditional absorption refrigeration cycles, the concentration of $0.28 \mathrm{~kg} / \mathrm{kg}$ is relatively low. The benefit of a low concentration is that it can reduce the pressure of the whole system. The temperature of the flue gas from the diesel engine was increased from $250{ }^{\circ} \mathrm{C}$ to $350{ }^{\circ} \mathrm{C}$ to test the performance of the combined system.

The variations in the primary parameters with the increase in the generation temperature were recorded and analysed, including the generator heat input, condenser 
heat output, absorber heat output, refrigeration output, total ammonia production, ammonia flux in desalination branch, pre-desalinated seawater production, and predesalinated seawater salinity. In a stable operation, the ammonia flux of the desalination branch is maintained by controlling the valve. Therefore, the refrigeration output of the desalination branch and the production of pre-desalinated seawater can also be maintained.

The exhaust gas heat input for the combined system was calculated based on the components and the temperature at the exhaust gas inlet and outlet. The volume fraction of the primary components in the exhaust gas was measured by the flue gas analyser. Because $\mathrm{N}_{2}, \mathrm{O}_{2}, \mathrm{CO}_{2}$, and $\mathrm{H}_{2} \mathrm{O}$ constitute approximately $99.7 \%$ of the volume in the exhaust gas, the enthalpy of the exhaust gas can be obtained.

\subsubsection{Experimental plan for pre-desalination}

Multiple repeated experiments were performed to test the performance of the predesalination system, and each experiment was divided into two stages. In the first stage, the initial seawater flow was $100 \mathrm{~L} / \mathrm{h}$. Under this seawater flow condition, the ammonia liquid flow at the inlet of the evaporator was adjusted to change the cooling capacity. If the cooling capacity is large, it increases the amount of sea ice, but the sea ice can easily form ice cubes, thus increasing the sea ice salinity. If the cooling capacity is small, the fluidity of the sea ice can be improved and the salinity can be reduced, but the amount of sea ice produced is little to none. Therefore, experiments are carried out to obtain the cooling capacity that is best suited for seawater crystallisation. The most suitable 
standard is more amounts of ice and low salinity. According to the flow and salinity of the sea ice obtained after the evaporator in the first stage, the flow and salinity of the seawater that will enter the evaporator in the second stage was adjusted. Low-salinity seawater is composed of sea salt and fresh water. Subsequently, the ammonia liquid flow at the inlet of the evaporator was adjusted again to obtain the most suitable cooling capacity in the second stage. After the two-stage freezing-assisted pre-desalination process, the flow and salinity of the pre-desalinated sea ice was obtained.

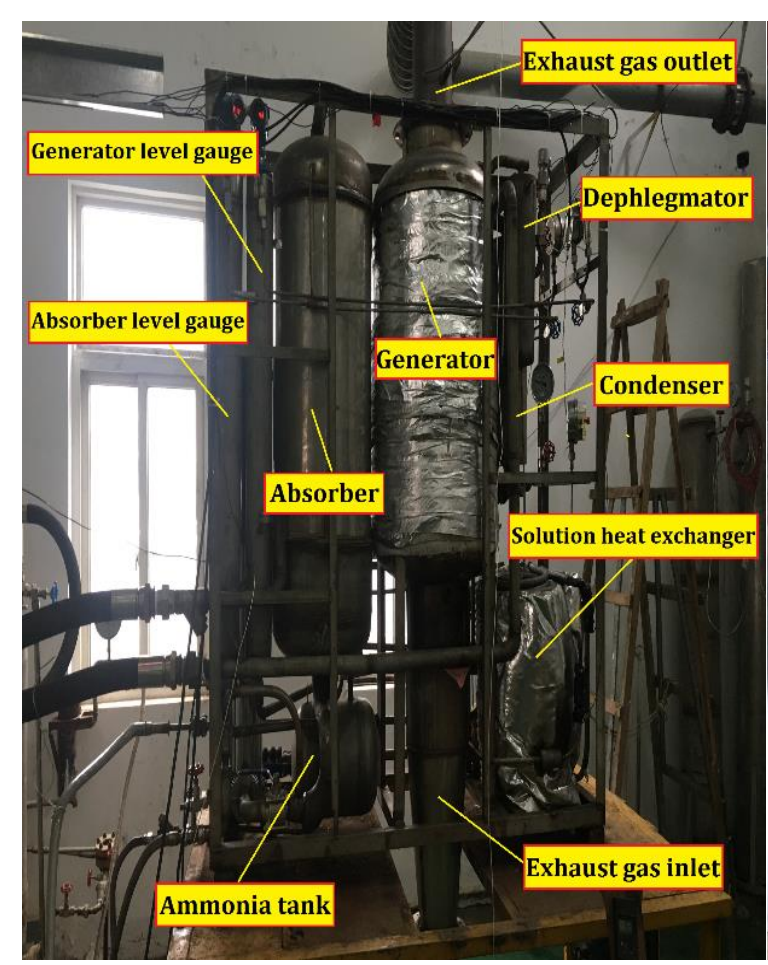

(a)

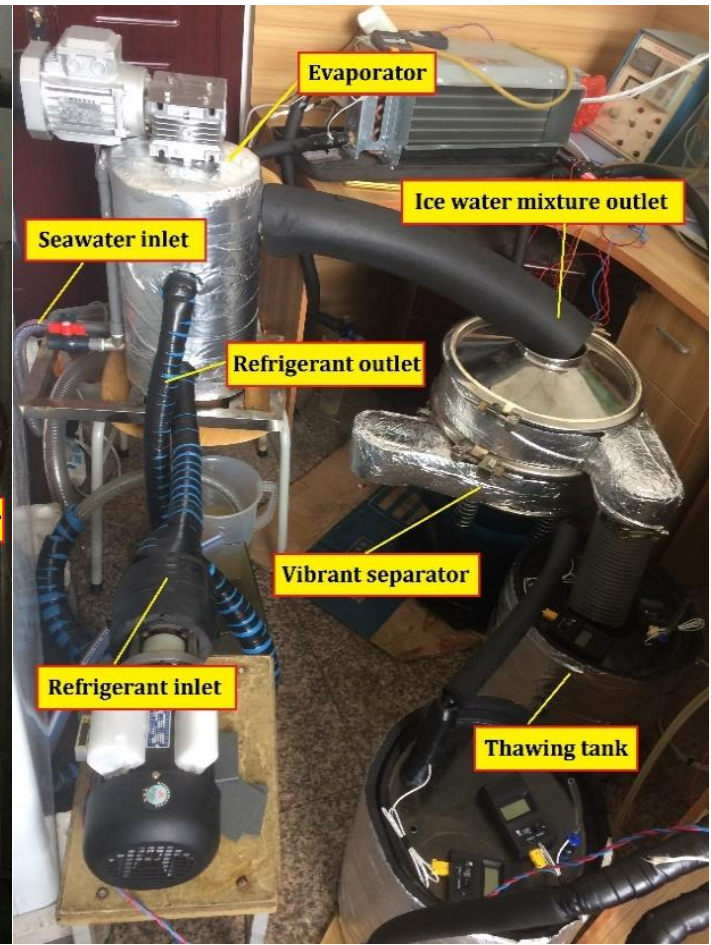

(b)

Fig.5 Photographs of the experimental platform: (a) Refrigeration system; (b) Desalination system

\subsection{Experimental results and discussion}

The experimental results of the combined system were obtained and compared with the theoretical results. Moreover, the pre-desalination system was tested separately to 


\subsubsection{Experimental results of the refrigeration and pre-desalination system}

The ammonia flux of the desalination branch is maintained by controlling the valve;

373 subsequently, the substep desalination experiment of the desalination branch is

374 performed. The primary and detailed experimental results are shown in Table 5. Table

3756 shows the average data of the substep experiment and the desalination rate at each

376 desalination stage. A set of selected experimental data for the whole combined system

377 is shown in Table 7.

378 Table 5 Experimental results of the pre-desalination system

\begin{tabular}{|c|c|c|c|c|c|c|c|c|c|c|c|c|c|c|c|}
\hline Exper & ent serial number & 1 & 2 & 3 & 4 & 5 & 6 & 7 & 8 & 9 & 10 & 11 & 12 & 13 & 14 \\
\hline \multirow{4}{*}{ Stage 1} & $\begin{array}{l}\text { Initial seawater } \\
\text { Flux }(\mathrm{L} / \mathrm{h})\end{array}$ & 100 & 100 & 100 & 100 & 100 & 100 & 100 & 100 & 100 & 100 & 100 & 100 & 100 & 100 \\
\hline & & 35.0 & 35.0 & 34.8 & 34.7 & 35.0 & 34.9 & 35.0 & 35.0 & 35.0 & 34.9 & 35.0 & 34.8 & 35.0 & 35.0 \\
\hline & $\begin{array}{l}\text { Seawater flux after } \\
\text { evaporator I (L/h) }\end{array}$ & 40.5 & 37.0 & 34.8 & 36.3 & 33.0 & 34.1 & 35.8 & 32.6 & 38.1 & 41.9 & 35.6 & 32.4 & 39.5 & 34.2 \\
\hline & Salinity (ppt) & 22.7 & 21.7 & 19.5 & 21.2 & 20.1 & 23.0 & 24.8 & 20.5 & 22.0 & 21.9 & 20.8 & 21.4 & 20.7 & 23.8 \\
\hline \multirow{4}{*}{ Stage 2} & $\begin{array}{l}\text { Seawater flux before } \\
\text { evaporator II (L/h) }\end{array}$ & 40.0 & 37.0 & 35.0 & 36.0 & 33.0 & 34.0 & 36.0 & 32.5 & 38.0 & 42.0 & 35.5 & 32.5 & 39.5 & 34.0 \\
\hline & Salinity (ppt) & 23.0 & 22.0 & 19.7 & 21.0 & 20.0 & 23.0 & 25.0 & 20.5 & 22.0 & 22.0 & 21.0 & 21.5 & 20.7 & 24.0 \\
\hline & $\begin{array}{l}\text { Pre-desalinated } \\
\text { seawater flux }(\mathrm{L} / \mathrm{h})\end{array}$ & 22.3 & 19.5 & 21.2 & 21.8 & 21.0 & 19.6 & 21.1 & 20.5 & 20.5 & 21.3 & 20.8 & 20.5 & 22.2 & 20.8 \\
\hline & Salinity (ppt) & 8.7 & 9.8 & 9.5 & 8.5 & 8.4 & 8.3 & 11.5 & 10.0 & 9.0 & 9.0 & 9.3 & 8.8 & 10.5 & 9.4 \\
\hline
\end{tabular}

379

380 Table 6 Desalination rate of each desalination stage

\begin{tabular}{llccc}
\hline & Seawater position & Flux $(\mathrm{L} / \mathrm{h})$ & Average Salinity $(\mathrm{ppt})$ & Desalination rate $(\%)$ \\
\hline \multirow{2}{*}{ Stage 1} & Initial seawater & 100 & 35.0 & \multirow{2}{*}{38.0} \\
& Seawater after evaporator I & 36.1 & 21.7 & \\
\hline \multirow{2}{*}{ Stage 2 } & Seawater before evaporator II & 36.1 & 21.8 & 57.3 \\
& Pre-desalinated seawater & 20.9 & 9.3 & \\
\hline
\end{tabular}

The experimental results demonstrate that the salinity of seawater was reduced to 

to the range of $8.3 \mathrm{ppt}$ to $11.5 \mathrm{ppt}$ after the second stage. On average, the salinity of the seawater was reduced to $21.7 \mathrm{ppt}$ and the desalination rate was $38.0 \%$ in the first-stage desalination process. The salinity of the pre-desalinated seawater was reduced to 9.3 ppt and the desalination rate was $57.3 \%$ in the second-stage desalination process. The desalination rate in the second stage was higher than that in the first stage, which is beneficial to the crystallisation of pure water.

Table 7 Experimental performance of the refrigeration and pre-desalination system

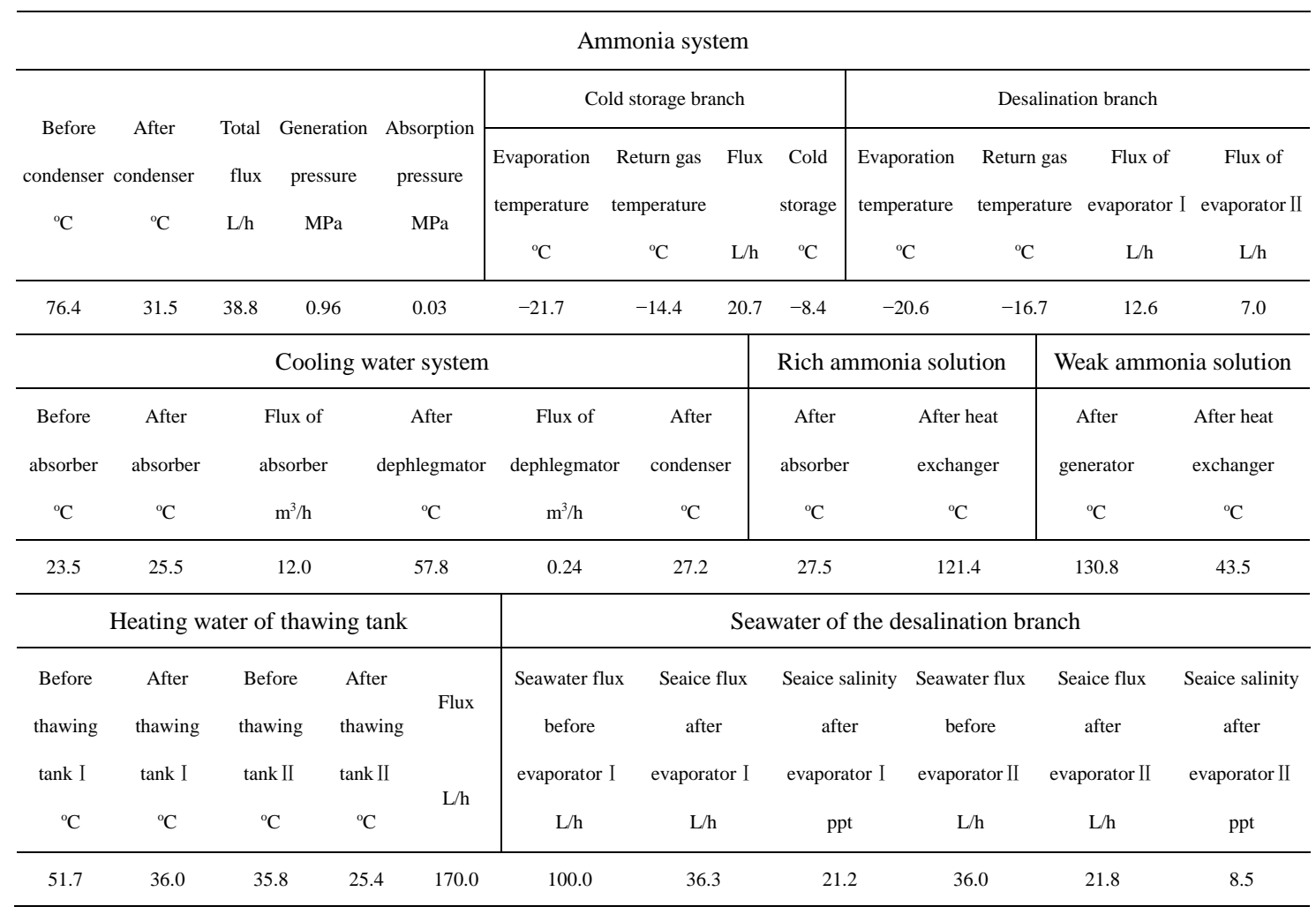

In this list of selected experimental data for the whole combined system, we found

391 that the total ammonia production was $38.8 \mathrm{~L} / \mathrm{h}$. The ammonia flux of the cold storage branch was $20.7 \mathrm{~L} / \mathrm{h}$ and that of the desalination branch was $19.6 \mathrm{~L} / \mathrm{h}$. The sum of the two branches was $40.3 \mathrm{~L} / \mathrm{h}$, which is slightly different than that of the total ammonia production. This difference is caused by measurement errors. Under these ammonia 
fluxes, the temperature of the cold storage reached $-8.4{ }^{\circ} \mathrm{C}$, while the evaporation temperature reached approximately $-21{ }^{\circ} \mathrm{C}$. With this evaporation temperature, the salinity of the pre-desalinated seawater was reduced to $8.5 \mathrm{ppt}$ through the two stages of the freezing desalination process. The production rate of the pre-desalinated seawater was $21.8 \mathrm{~L} / \mathrm{h}$. If the desalination scale or the refrigeration requirement for cold storage is increased, the temperature of the inlet exhaust gas can be further increased to improve the refrigeration output for the whole system.

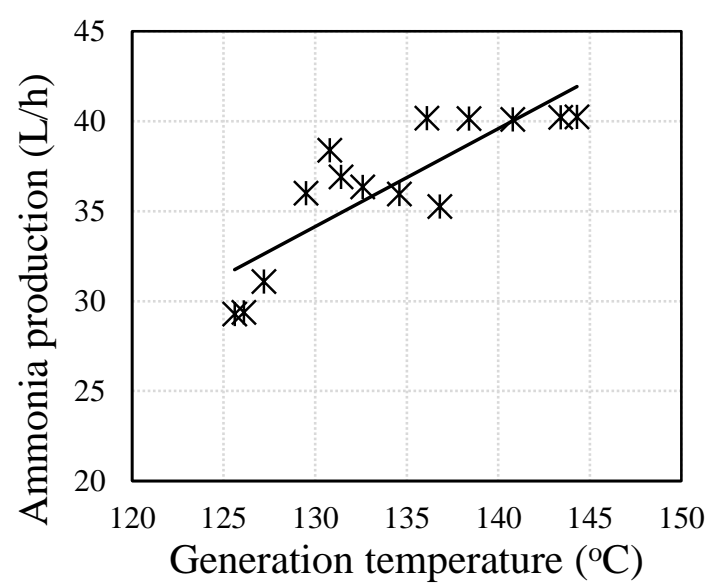

(a)

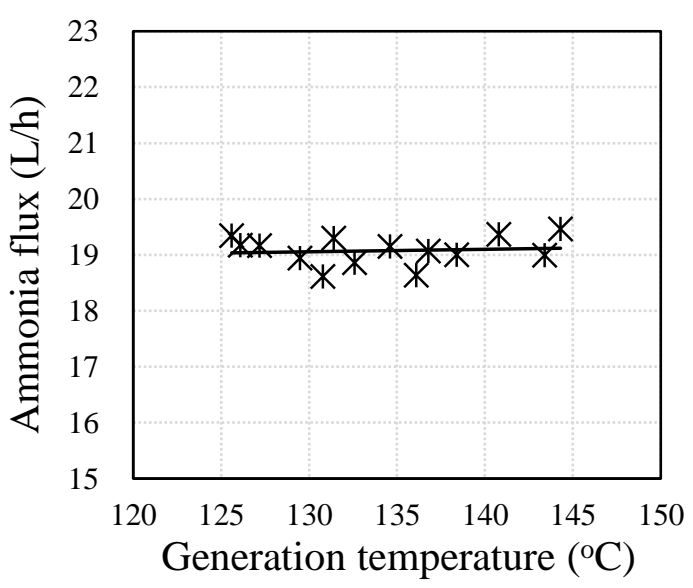

(b)

Fig.6 Ammonia output: (a) Total ammonia production;

(b) Ammonia flux of pre-desalination branch

Figure 6(a) shows the relationship between the total ammonia production and the generation temperature. The result shows that, with the continuous improvement in the generation temperature, the total production of ammonia increases. When the generation temperature reached $140{ }^{\circ} \mathrm{C}$, the total ammonia production increased to 40 L/h. Figure 6(b) illustrates the relationship between the ammonia flux of the desalination branch and the generation temperature. We found that through the control of the valve, the ammonia flux was maintained between $18 \mathrm{~L} / \mathrm{h}$ and $20 \mathrm{~L} / \mathrm{h}$. 
412

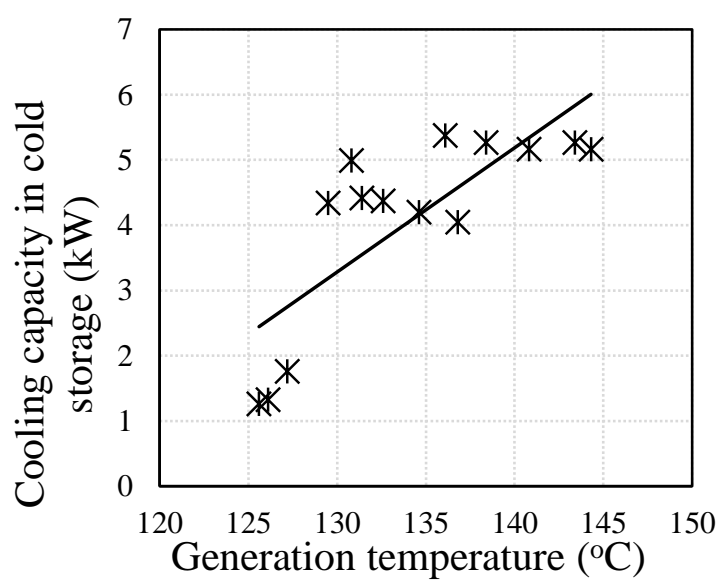

(a)

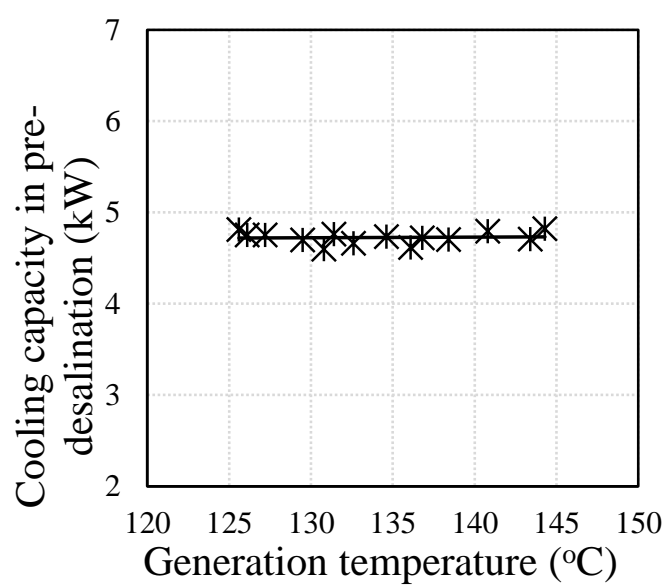

(b)

Fig.7 Cooling capacity of two branches: (a) Cold storage branch;

(b) Pre-desalination branch

Figure 7 depicts the cooling capacity performances of the two branches. The cooling capacity of the cold storage branch ranged from $1.2 \mathrm{~kW}$ to $5.2 \mathrm{~kW}$, as shown in Fig.7(a).

The cooling capacity of the pre-desalination branch was maintained at approximately 4.7 kW, as shown in Fig. 7(b). As indicated in the figure, a rising trend in the cooling capacity occurs in the cold storage branch with the continuous improvement of the generation temperature, while the cooling capacity in the pre-desalinated branch is maintained at a constant.

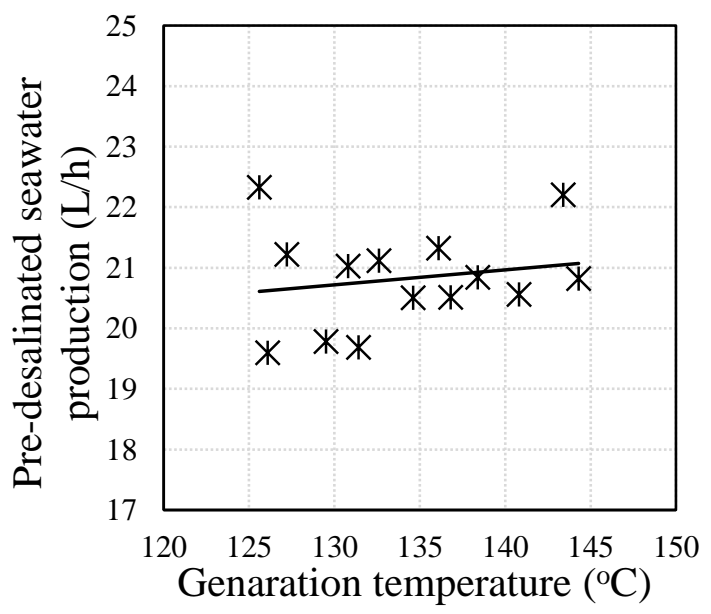

(a)

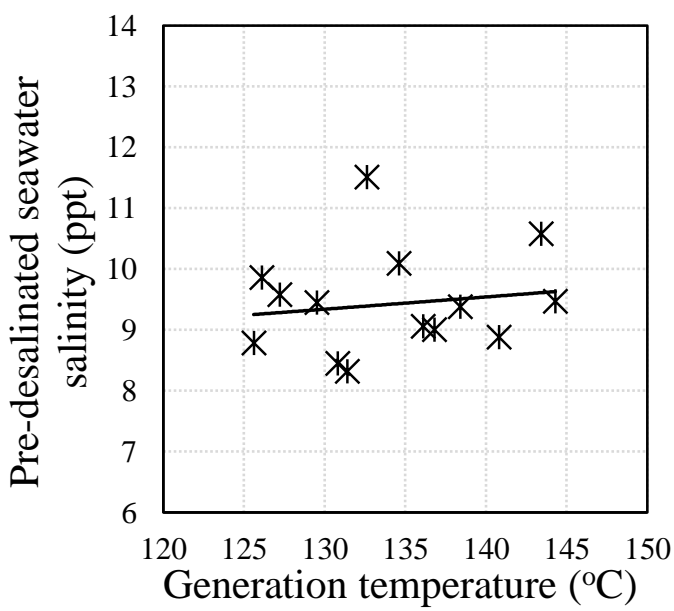

(b)

Fig.8 Pre-desalinated seawater output: (a) Production; (b) Salinity 

seawater and the generation temperature. The result shows that the pre-desalinated seawater production was primarily maintained between $20 \mathrm{~L} / \mathrm{h}$ and $22 \mathrm{~L} / \mathrm{h}$. Figure $8(\mathrm{~b})$

427 shows the performance of the pre-desalinated seawater salinity. We found that the predesalinated seawater salinity was primarily maintained below $10 \mathrm{ppt}$, thus achieving the expected freezing-assisted desalination target.

\subsubsection{Comparison of system performances between experimental and theoretical} results output, and system COP were experimentally obtained and compared with the theoretical results.

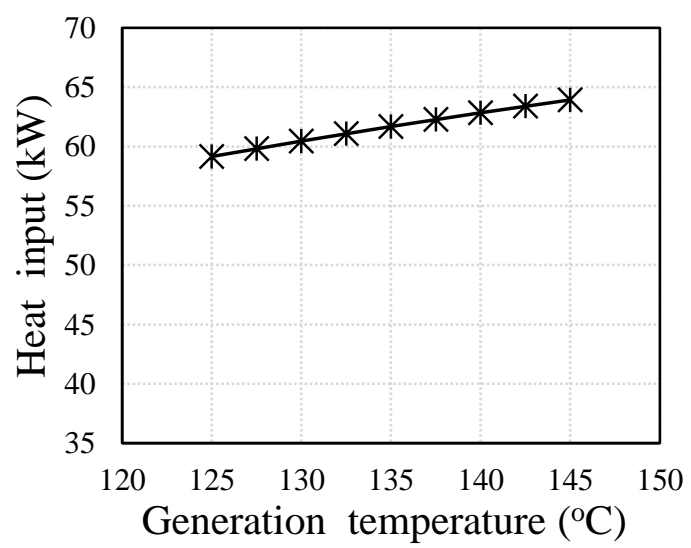

(a)

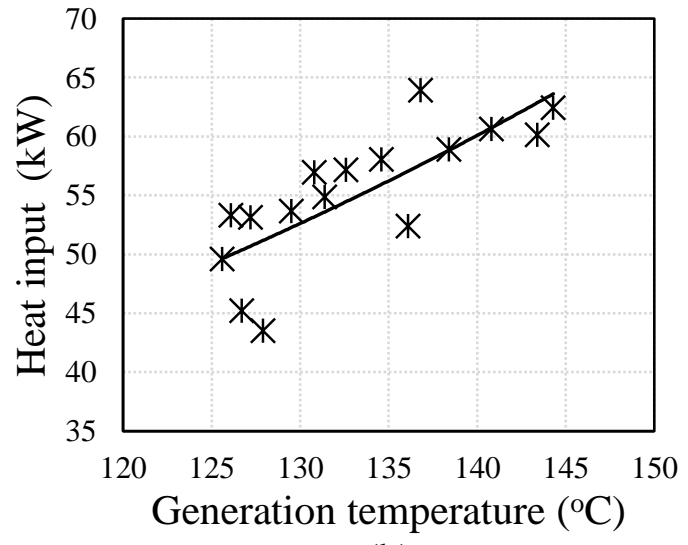

(b)

Fig.9 Comparison of generator heat input: (a) Theoretical generator heat input; 
was detected by a flue gas analyser, and the results of the experimental generator heat

441

442 input obtained according to the flue gas composition[33] are shown in Fig. 9(b). The experimental and theoretical generator heat inputs were compared. The theoretical heat input ranged from $58 \mathrm{~kW}$ to $64 \mathrm{~kW}$, and the experimental heat input ranged from 50 $\mathrm{kW}$ to $64 \mathrm{~kW}$; meanwhile, the generation temperature ranged from $125^{\circ} \mathrm{C}$ to $145^{\circ} \mathrm{C}$. The experimental generator heat input showed a faster increasing trend than the theoretical generator heat input. The error of the experimental and theoretical curves was approximately $8 \%$.

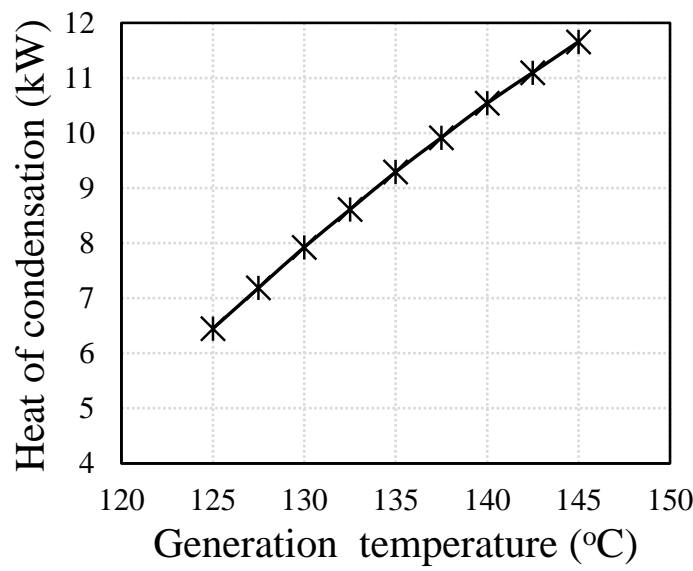

(a)

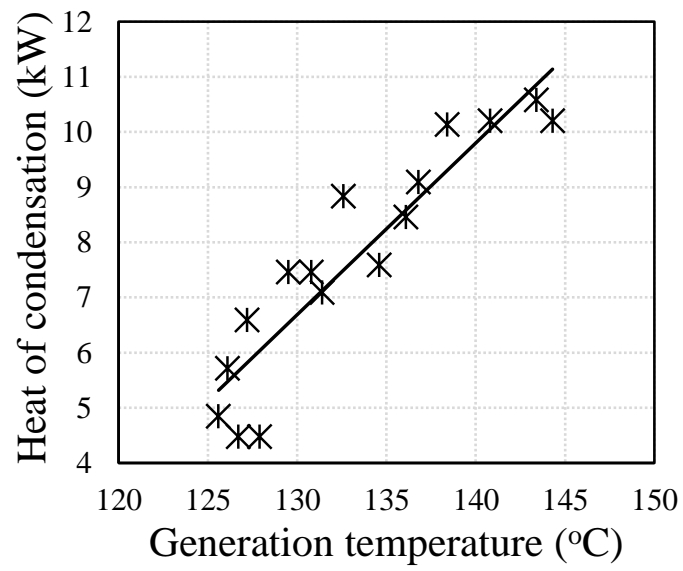

(b)

Fig.10 Comparison of condenser heat output: (a) Theoretical condenser heat output;

(b) Experimental condenser heat output

The comparison between the theoretical and experimental results of the system heat of condensation is shown in Fig. 10. The theoretical heat of condensation obtained according to Eq. (10) and Eq. (11) ranged from $6 \mathrm{~kW}$ to $12 \mathrm{~kW}$, and the experimental heat of condensation ranged from $5 \mathrm{~kW}$ to $11 \mathrm{~kW}$. Meanwhile, the generation temperature ranged from $125^{\circ} \mathrm{C}$ to $145^{\circ} \mathrm{C}$. In the same generation temperature range, the experimental heat of condensation was lower than the theoretical heat of 
condensation by approximately $10 \%$. Because the unit operation time was during the winter, the indoor air temperature was low, i.e. approximately $10^{\circ} \mathrm{C}$. Considering the heat loss caused by the heat exchange between the refrigerant and air, the actual heat of condensation would be slightly greater than the measured data.

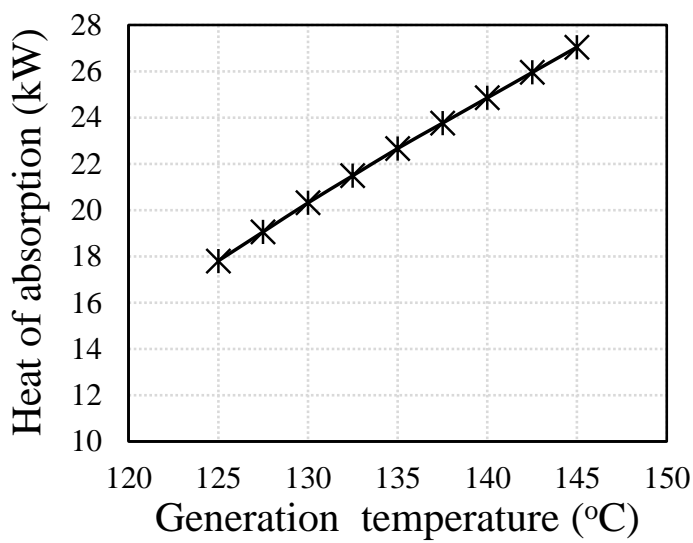

(a)

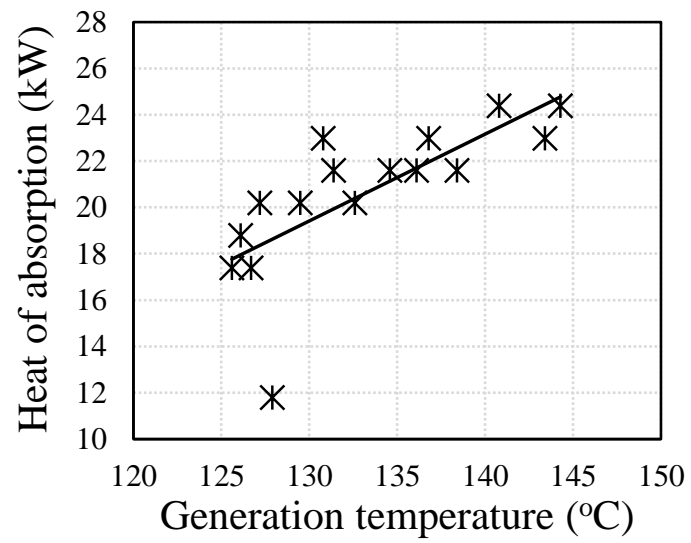

(b)

Fig.11 Comparison of absorber heat output: (a) Theoretical absorber heat output; (b) Experimental absorber heat output

The comparison between the theoretical and experimental results of the system heat of absorption is shown in Fig. 11. The theoretical heat of absorption obtained according to Eq. (12) and Eq. (13) ranged from $18 \mathrm{~kW}$ to $27 \mathrm{~kW}$, and the experimental heat of absorption ranged from $17 \mathrm{~kW}$ to $25 \mathrm{~kW}$, while the generation temperature ranged from $125^{\circ} \mathrm{C}$ to $145^{\circ} \mathrm{C}$. In the same generation temperature range, the experimental absorber heat output was lower than the theoretical absorber heat output by approximately $7 \%$. Considering the heat exchange between the refrigerant and the winter air, the actual heat of absorption would be slightly greater than the measured data. 


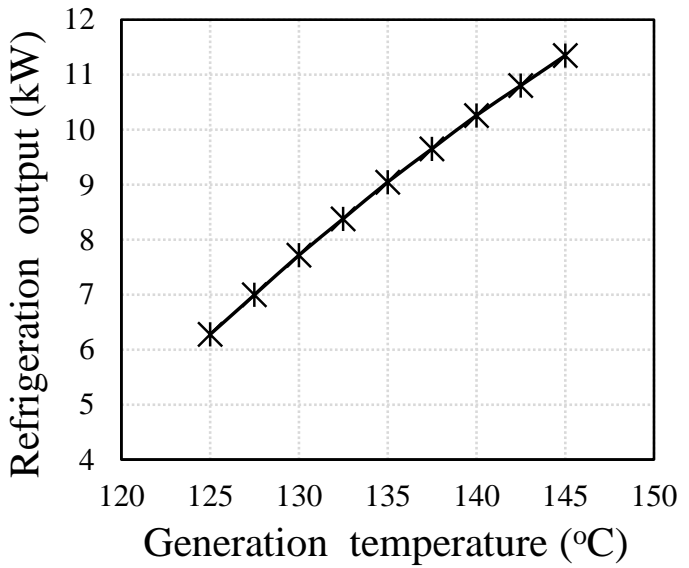

(a)

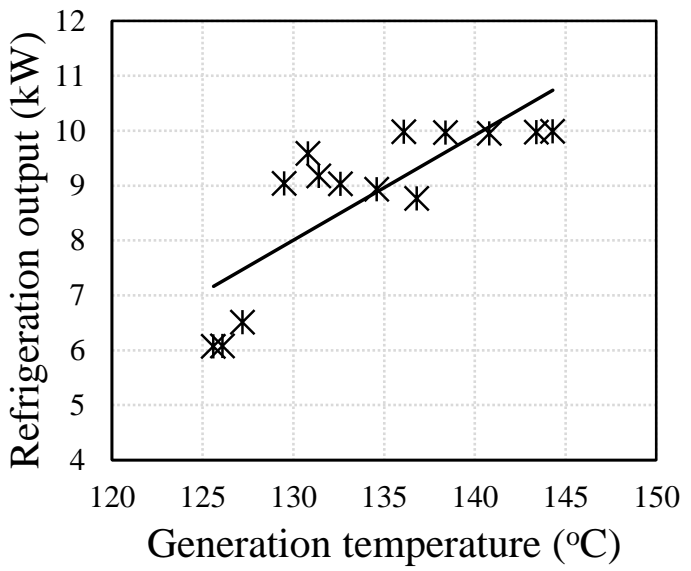

(b)

Fig.12 Comparison of refrigeration output: (a) Theoretical refrigeration output; (b)

$$
\text { Experimental refrigeration output }
$$

The comparison between the theoretical and experimental results of the system refrigeration output is shown in Fig.12. The theoretical refrigeration output obtained according to Eq. (14) and Eq. (15) ranged from $6.3 \mathrm{~kW}$ to $11.3 \mathrm{~kW}$, and the experimental refrigeration output ranged from $6.1 \mathrm{~kW}$ to $9.9 \mathrm{~kW}$. Meanwhile, the generation temperature ranged from $125^{\circ} \mathrm{C}$ to $145{ }^{\circ} \mathrm{C}$. We found that the refrigeration output, which is a function of the ammonia liquid balance in the system, exhibited a large gradient when the generation temperature was close to $130{ }^{\circ} \mathrm{C}$. When the generation temperature is close to $130^{\circ} \mathrm{C}$, the total ammonia production of the system is increased, and the ammonia liquid stored in the ammonia liquid tank is sufficient. At this time, the ammonia liquid flow at the outlet of the ammonia liquid tank is increase by adjusting the valve, which leads to the cooling capacity exhibiting a large gradient. 


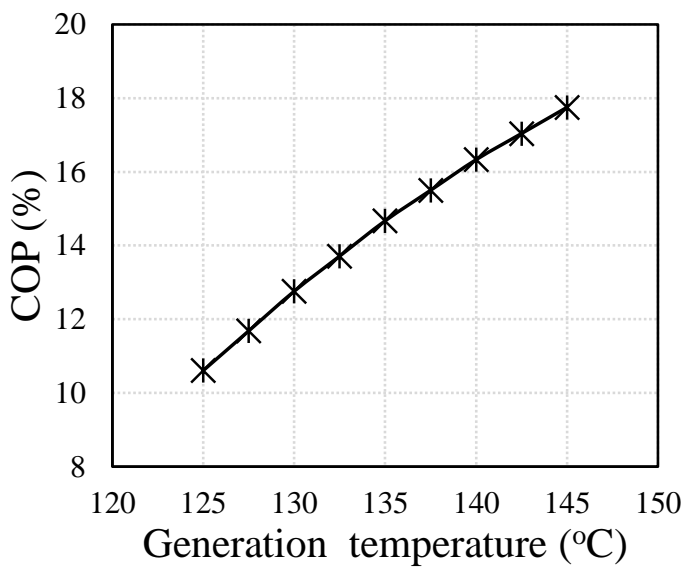

(a)

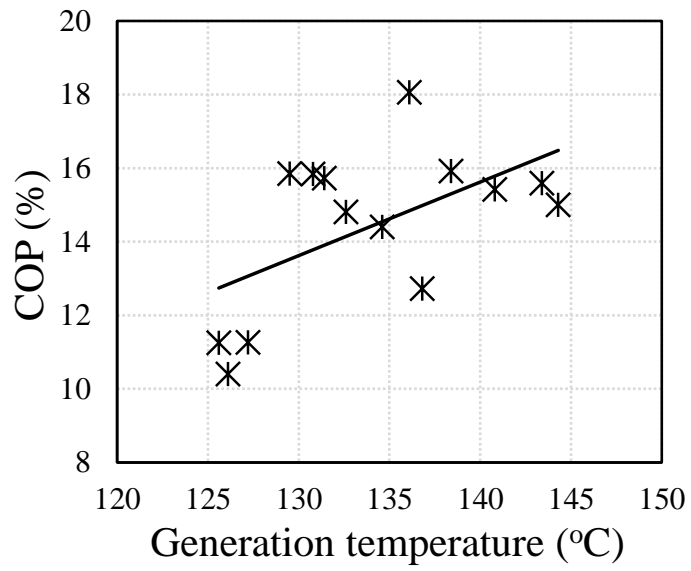

(b)

Fig.13 Comparison of COP: (a) Theoretical COP; (b) Experimental COP experimental COP was lower than the theoretical COP by approximately $7 \%$.

\section{Economic analysis}

The cost of the general RO desalination device primarily includes two parts: the electricity consumption cost and the membrane replacement cost.

$$
F_{\text {total }}=F_{\text {elec }}+F_{\text {mem }}+F_{\text {else }}
$$

The electricity consumption cost is defined as

where $F_{u}$ is the unit electricity consumption cost (yuan/kWh), $M_{w}$ is the operation power of the $\mathrm{RO}$ device $(\mathrm{kW})$, and $M_{t}$ is the operation time of the RO device 
The membrane replacement cost is defined as[34]

where $M_{o}$ is the component cost (yuan/piece), $M_{p}$ is the component output (L/d),

and $M_{L}$ is the component lifetime (year).

$F_{\text {else }}$ includes the labour cost, spare parts cost, and reagent cost. For small-scale RO desalination devices, $F_{\text {else }}$ is low and even negligible.

According to Eq. (37), the electricity consumption cost primarily depends on the operating power and operating time of the RO device. The operating power of the RO device is associated with the salinity of the influent seawater. Figure 14 shows the relationship between the operating power of the RO device and the salinity of influent seawater. The experiment device is a small-scale RO device (Model: YB-SWRO-500L) significantly reduced the operating power of the RO device.

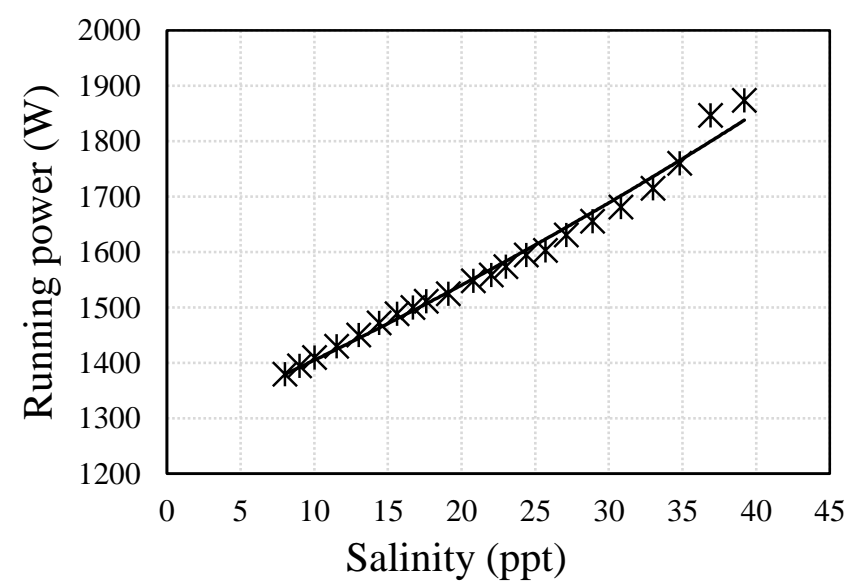
and the salinity of influent seawater

Fig.14 Relationship between the operating power of the small-scale RO device Under the same membrane lifetime, the total desalination cost of the brackish water 
was lower than the total desalination cost of the initial seawater. Furthermore, under the same fresh water output, the membrane lifetime increased with the decrease in the seawater salinity. Generally, a long lifetime has little impact on the total cost; however, if mis-operation or a change in influent water causes the component lifetime to shorten, it can significantly affect the total cost.

The average salinity of the pre-desalinated seawater was 9.3 ppt after the two-stage freezing-assisted desalination process. For the small-scale RO device of YB-SWRO$500 \mathrm{~L}$, we assumed that the operating time was $12 \mathrm{~h} /$ day. The total RO cost of the predesalinated seawater was compared with the total RO cost of the initial seawater with an average salinity of $35 \mathrm{ppt}$, and the result is shown in Fig. 15. Finally, the total cost of freezing-assisted RO was calculated to be less than the total cost of general RO by approximately $26 \%$.

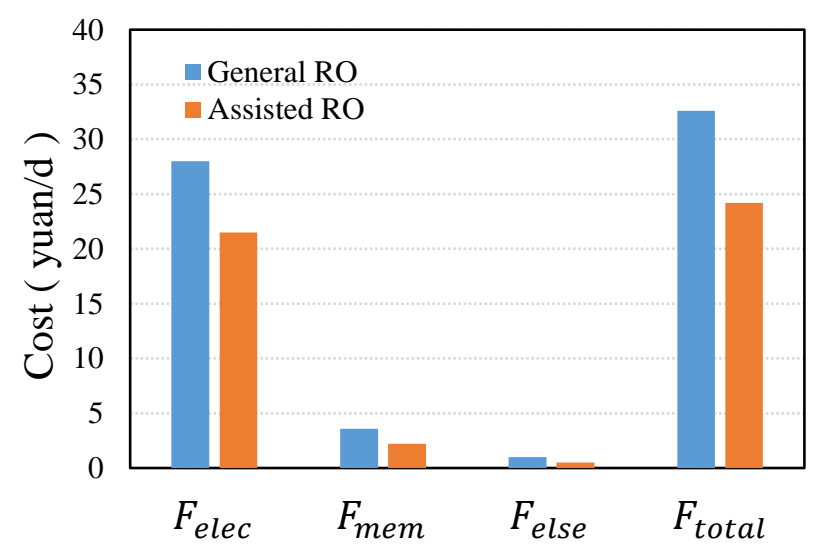

Fig.15 General RO and assisted RO cost comparison

\section{Conclusion}

We herein introduced an absorption refrigeration and two-stage freezing-assisted desalination system for recovering waste heat from marine diesel engine flue gas. The 
refrigeration produced by this system could be used for low-temperature cold storage and seawater freezing-assisted desalination. A mathematical model and solution procedure of the system were developed to predict its performance, and an experimental platform was established to evaluate its performance. During the experiment, the total ammonia production was continuously increased by the continuous increase in the influent flue gas temperature. The ammonia flux of the desalination branch was maintained by controlling the valve, while the ammonia flux of the cold storage branch was continuously increased. Consequently, stable production of pre-desalinated seawater and a low-temperature cold storage were obtained. Based on our analysis, the following conclusions were drawn.

- With the concentration of the ammonia-water rich solution at $0.28 \mathrm{~kg} / \mathrm{kg}$ and the generation temperature increasing from $125^{\circ} \mathrm{C}$ to $145^{\circ} \mathrm{C}$, the system COP could be increased from $10 \%$ to $16 \%$. The total refrigeration output varied from $6.1 \mathrm{~kW}$ to $9.9 \mathrm{~kW}$ and the cooling capacity of the cold storage sub-branch was increased from $1.2 \mathrm{~kW}$ to $5.2 \mathrm{~kW}$, and the cooling capacity of the predesalination branch was maintained at approximately $4.7 \mathrm{~kW}$.

- With the pre-desalination process, the production of pre-desalinated seawater was primarily maintained between $20 \mathrm{~L} / \mathrm{h}$ and $22 \mathrm{~L} / \mathrm{h}$ when the flux of the initial seawater was $100 \mathrm{~L} / \mathrm{h}$. Furthermore, the salinity of the pre-desalinated seawater was reduced to below $10 \mathrm{ppt}$ from an initial value of $35 \mathrm{ppt}$.

- The generator heat input, condenser heat output, absorber heat output, refrigeration output, and system COP increased as the generation temperature 

seawater remained at the same level as the generation temperature varied.

- The cost of RO seawater desalination could be reduced by $26 \%$ through

\section{Acknowledgements}

The authors would like to acknowledge the financial support from National Natural

scientific research business fees special of China (201713034).

\section{References}

[1]. Deng, B., Q. Tang and M. Li, Study on the steam-assisted Brayton air cycle for exhaust heat recovery of internal combustion engine. Applied Thermal Engineering, 2017. 125.

572 [2]. Fu, J., et al., Energy and exergy analysis on gasoline engine based on mapping characteristics 573 experiment. Applied Energy, 2013. 102(2): p. 622-630.

574 [3]. Yüksel, F. and M.A. Ceviz, Thermal balance of a four stroke SI engine operating on hydrogen as a supplementary fuel. Energy, 2003. 28(11): p. 1069-1080.

576 [4]. Taymaz, I., An experimental study of energy balance in low heat rejection diesel engine. Energy, 577 2006. 31(2-3): p. 364-371.

578 [5]. Galindo, J., et al., Further analysis of a compression-expansion machine for a Brayton Waste Heat 579 Recovery cycle on an IC engine. Applied Thermal Engineering, 2017.

580 [6]. Gopal, N.K., et al., Thermodynamic Analysis of a Diesel Engine Integrated with a PCM Based 581 Energy Storage System. International Journal of Thermodynamics, 2010. 13(1).

582 [7]. Kyriakidis, F., et al., Modeling and optimization of integrated exhaust gas recirculation and multi583 stage waste heat recovery in marine engines. Energy Conversion \& Management, 2017. 151: p. 286-295.

584 [8]. Kim, S.L., et al., Evaluation of automotive waste heat recovery for various driving modes. Energy, 585 2016. 106: p. 579-589.

586 [9]. Chen, Y., W. Han and H. Jin, Thermodynamic performance optimization of the absorptiongeneration process in an absorption refrigeration cycle. Energy Conversion \& Management, 2016. 126:

588 p. 290-301.

589 [10]. Salek, F., A.N. Moghaddam and M.M. Naserian, Thermodynamic analysis of diesel engine coupled 
with ORC and absorption refrigeration cycle. Energy Conversion \& Management, 2017. 140: p. 240-246. [11]. Maryami, R. and A.A. Dehghan, An exergy based comparative study between LiBr/water absorption refrigeration systems from half effect to triple effect. Applied Thermal Engineering, 2017. 124(9): p. 103-123.

[12]. Cerezo, J., et al., Experimental study of an ammonia - water bubble absorber using a plate heat exchanger for absorption refrigeration machines. Applied Thermal Engineering, 2009. 29(5): p. 1005 1011.

[13]. Arshi Banu, P.S. and N.M. Sudharsan, Review of water based vapour absorption cooling systems using thermodynamic analysis. Renewable \& Sustainable Energy Reviews, 2018. 82.

[14]. Ibrahim, N.I., F.A. Al-Sulaiman and F.N. Ani, Performance characteristics of a solar driven lithium bromide-water absorption chiller integrated with absorption energy storage. Energy Conversion \& Management, 2017. 150: p. 188-200.

[15]. Moreno, D., et al., Absorption refrigeration cycles based on ionic liquids: Refrigerant/absorbent selection by thermodynamic and process analysis. Applied Energy, 2018. 213: p. 179-194.

[16]. Wu, X., S. Xu and M. Jiang, Development of bubble absorption refrigeration technology: A review. Renewable \& Sustainable Energy Reviews, 2018. 82.

[17]. Alelyani, S.M., et al., Techno-economic analysis of combined ammonia-water absorption refrigeration and desalination. Energy Conversion \& Management, 2017. 143: p. 493-504.

[18]. Sun, J., L. Fu and S. Zhang, A review of working fluids of absorption cycles. Renewable \& Sustainable Energy Reviews, 2012. 16(4): p. 1899-1906.

[19]. Srikhirin, P., S. Aphornratana and S. Chungpaibulpatana, A review of absorption refrigeration technologies. Renewable \& Sustainable Energy Reviews, 2000. 5(4): p. 343-372.

[20]. Li, Y. and R. Hu, Exergy-analysis based comparative study of absorption refrigeration and electric compression refrigeration in CCHP systems. Applied Thermal Engineering, 2016. 93: p. 1228-1237.

[21]. Kang, Z., et al., Research Status of Ice-storage Air-conditioning System. Procedia Engineering, 2017. 205: p. 1741-1747.

[22]. Song, X., et al., Study of economic feasibility of a compound cool thermal storage system combining chilled water storage and ice storage. Applied Thermal Engineering, 2018.

[23]. Liu, S., et al., Impacts on the solidification of water on plate surface for cold energy storage using ice slurry. Applied Energy, 2017.

[24]. Tamasauskas, J., et al., Development and validation of a solar-assisted heat pump using ice slurry as a latent storage material. Solar Energy, 2012. 21(6): p. 837-846.

[25]. Xie, C., et al., A direct contact type ice generator for seawater freezing desalination using LNG cold energy. Desalination, 2017.

[26]. Jayakody, H., R. Al-Dadah and S. Mahmoud, Computational fluid dynamics investigation on indirect contact freeze desalination. Desalination, 2017. 420: p. 21-33.

[27]. Mandri, Y., et al., Parametric study of the sweating step in the seawater desalination process by indirect freezing. Desalination, 2011. 269(1-3): p. 142-147.

[28]. Shapiro, J., Freezing-Out, a Safe Technique for Concentration of Dilute Solutions. Science, 1961. 133(3470): p. 2063.

[29]. Rich, A., et al., Sea water desalination by dynamic layer melt crystallization: Parametric study of the freezing and sweating steps. Journal of Crystal Growth, 2012. 342(1): p. 110-116.

[30]. Luo, C.S., W.W. Chen and W.F. Han, Experimental study on factors affecting the quality of ice crystal during the freezing concentration for the brackish water. Desalination, 2010. 260(1 - 3): p. 231- 
238.

635 [31]. Williams, P.M., et al., Technology for freeze concentration in the desalination industry. 636 Desalination, 2015. 356(3): p. 314-327.

637 [32].Ziegler, B. and C. Trepp, Equation of state for ammonia-water mixtures. International Journal of 638 Refrigeration, 1984. 7(2): p. 101-106.

639 [33]. Du, S., R.Z. Wang and X. Chen, Development and experimental study of an ammonia water 640 absorption refrigeration prototype driven by diesel engine exhaust heat. Energy, 2017. 130.

641 [34].C.J. Gao and G.L. Ruan, Seawater desalination technology and engineering. Chemical Industry 642 Press, 2016: p. 296.

643 